\title{
Hexavalent Chromium Reduction at the Polypyrrole-Coated 304- Stainless-Steel-Electrode in a Filter-Press-Type Reactor
}

\author{
E.E. Villalobos-Neri ${ }^{1}$, U. Páramo-García ${ }^{1, *}$, H. Hernández-Escoto ${ }^{2, *}$, R. Mayen-Mondragon ${ }^{3}$, \\ N.V. Gallardo-Rivas ${ }^{1}$ \\ ${ }^{1}$ Tecnológico Nacional de México/I. T. Cd. Madero, Centro de Investigación en Petroquímica, Prol. \\ Bahía de Aldhair y Av. de las Bahías, Parque de la Pequeña y Mediana Industria, 89600, Altamira, \\ Tamaulipas, MÉXICO \\ ${ }^{2}$ Universidad de Guanajuato, Departamento de Ingeniería Química, Noria Alta s/n, 36050, Guanajuato, \\ Gto., MÉXICO. \\ ${ }^{3}$ Polo Universitario de Tecnología Avanzada, Facultad de Química, Universidad Nacional Autónoma \\ de México, Vía de la Innovación 410, Autopista MTY-Aeropuerto Km. 10, Parque PIIT, 66629, \\ Apodaca, Nuevo León, MÉXICO. \\ *E-mail: uparamo@itcm.edu.mx; hhee@ugto.mx
}

Received: 30 May 2021 / Accepted: 14 July 2021 / Published: 10 September 2021

In this work, the reduction of $\mathrm{Cr}(\mathrm{VI})$ to $\mathrm{Cr}$ (III) in a filter-press-type electrochemical-reactor is studied. The working electrode within the reactor is a polypyrrole-coated 304-stainless-steel plate. The polypyrrole was electropolimerized via 40 cyclic-voltammetry cycles. The deposit was characterized by Fourier Transform Infrared Spectroscopy, Optical Microscopy and Scanning Electron Microscopy. The $\mathrm{Cr}(\mathrm{VI})$-ions solution was recirculated within the filter-press-type reactor and its concentration was monitored via the 1,5-diphenylcarbazide colorimetric technique. It was proposed that the $\mathrm{Cr}(\mathrm{VI})$ removal process consists of a mechanism combining ion transport between the solution stream and the electrode, and reduction of $\mathrm{Cr}(\mathrm{VI})$ at the electrode. A mathematical model was then derived to describe the $\mathrm{Cr}(\mathrm{VI})$ evolution within the solution stream, and at the PPY electrode-layer. The model was validated with experimental data.

Keywords: conductive polymers, ion exchange, reduction, water contamination, mathematical model.

\section{$\underline{\text { FULL TEXT }}$}

(C) 2021 The Authors. Published by ESG (www.electrochemsci.org). This article is an open access article distributed under the terms and conditions of the Creative Commons Attribution license (http://creativecommons.org/licenses/by/4.0/). 